(1)

CrossMark

\section{Insight into the impact of the COVID-19 epidemic on tuberculosis burden in China}

\author{
To the Editor:
}

We are interested in an article published in the journal recently, entitled "The potential impact of COVID-19-related disruption on tuberculosis burden". The study used a mathematical model to estimate the relative impact of reductions in social contacts and health services on tuberculosis (TB) burden due to the coronavirus disease 2019 (COVID-19) epidemic. There included data and projections on China, being one of 22 high TB burden countries for both TB and multidrug-resistant TB cases. COVID-19, which has spread rapidly and enveloped most of the world, is a unique global public health crisis for the century. By the end of January 2020, The World Health Organization declared COVID-19 outbreak a global health emergency and called for moves to stop the transmission of this virus. Accordingly, comprehensive and large-scale preventive and control measures were launched in February 2020. As McQuAID et al. [1] reported, COVID-19 outbreak had an impact on both short-term and long-term global TB control. In addition to model prediction, little is known about the specific impact of the COVID-19 epidemic on TB. Here, we compared the actual epidemic data on TB released monthly by the China National Health Commission from January to May of 2019 and 2020. In 2020, the numbers of newly registered patients with TB nationwide from January to May were 67682, 44933, 73427, 85684 and 83385 [2-6], with a decrease of $24 \%, 39 \%, 25 \%, 15 \%$ and $13 \%$, respectively compared to the same periods in the previous year (figure 1). Over the same period in 2020, the number of confirmed cases with COVID-19 peaked 68033 in February and has been sharply declining since March. Only 143 cases were reported nationwide in May, a decrease of $99.8 \%$ from the peak [3-6]. The declines in TB registrations may partly be related to the COVID-19 epidemic, especially in February 2020. The above figures indicate that the COVID-19 outbreak might serve as a double-edged sword for TB control. On the one hand, comprehensive preventive measure against COVID-19, including self-quarantine, social distancing and wearing facial masks, had reduced the spread of TB transmission in the community. In addition, early in the COVID-19 outbreak, large number of COVID-19 cases were identified and hospitalised within a short period of time, disrupting other routine medical practices and medical resources. Designated hospitals that previously served for TB diagnosis and treatment had been temporarily identified as designated hospitals for COVID-19 diagnosis and treatment [7]. Meanwhile, suspected and confirmed TB cases might be reluctant to go to hospital for fear of COVID-19 infection. This might cause diagnostic delay for the suspected TB patients but increase the risk of TB transmission in households and communities. Figures showed that numbers of newly registered TB cases increased after the COVID-19 was gradually brought under control from March, 2020, and the gap was also narrowing month by month compared with the same periods in the previous year. Both the numbers of new TB infections due to the delay of diagnosis and treatment of the source of infections during the COVID-19 epidemic and of TB cases reduced by comprehensive measures against COVID-19 are worthy of further study. The disclosure of national TB registration data in the coming months may provide a better answer. The above-mentioned situation only reflected the impact of COVID-19 outbreak on TB epidemic at the national level; however, there might have been different pictures in each of the provinces, depending on the severity of the local COVID-19 epidemic. In addition, there might be other interactions and causality deserved to be explored between COVID-19 and TB, such as whether COVID-19 cases would boost the development of active TB, or vice versa [8-10]. It was also reported that COVID-19 had a modest impact on clinical symptoms and prognosis of anti-TB treatment in the short term but long-term impact still needed to be explored $[8,9]$.

@ERSpublications

In the early stage of the COVID-19 outbreak, it may have both positive and negative impact on tuberculosis control, and in the long run, it may reduce the disease burden of tuberculosis if COVID-19 could be effectively controlled https://bit.ly/2ZObLzL

Cite this article as: Chen $\mathrm{H}$, Zhang K. Insight into the impact of the COVID-19 epidemic on tuberculosis burden in China. Eur Respir J 2020; 56: 2002710 [https://doi.org/10.1183/13993003.02710-2020]. 
FIGURE 1 Comparisons of newly registered tuberculosis (TB) cases nationwide in China from January to May of 2019 and 2020. Note that the number of confirmed coronavirus disease 2019 cases peaked at 68033 in February 2020 and has been declining sharply since March, with only 143 cases reported nationwide in May.

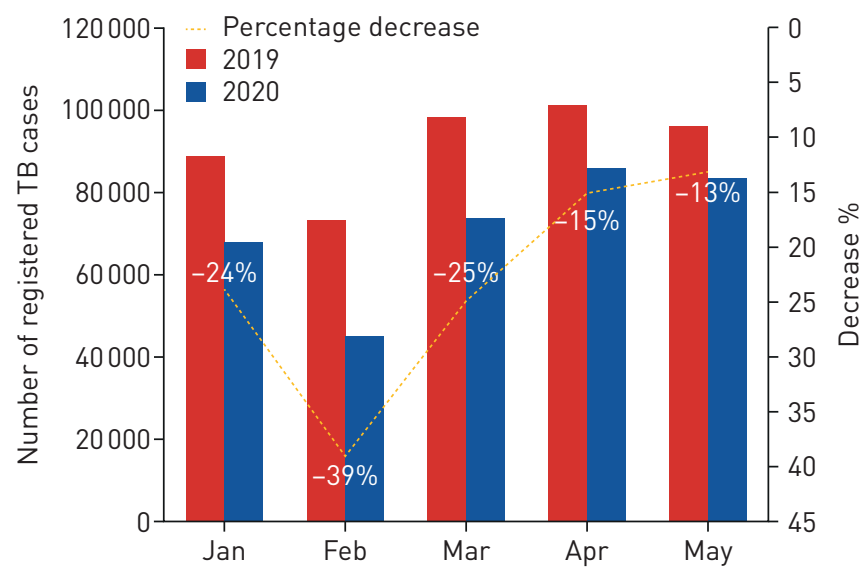

In the long run, we do not think that the number of TB cases and deaths will increase as predicted by the model reported by McQuAID et al. [1]. Firstly, population-based comprehensive interventions against COVID-19 have been well implemented and proven to be effective, and the spread of the virus has almost been tamed in China. It is assumed that the COVID-19 epidemic might be resurgent again; nevertheless, it should be at the local level and would be brought under control within a short period. The control of a COVID-19 epidemic related to Xinfadi market in Beijing verified the assumption. Thirdly, COVID-19 not only saddles on disaster, but also provides experience in fighting against TB. People of all walks of life have learned and practised the intervention programmes related to respiratory infectious diseases, i.e. personal hygiene and protection, including wearing masks in particular. In addition, the government is also taking this opportunity to further improve the public health infrastructure. The above measures will also enhance the capacity for diagnosis, treatment and management of $\mathrm{TB}$ patients, so as to reduce the disease burden of TB.

Hongguang Chen ${ }^{1}$ and Konglai Zhang ${ }^{2}$

${ }^{1}$ Peking University Sixth Hospital, Beijing, China. ${ }^{2}$ Dept of Epidemiology, Institute of Basic Medical Sciences, Chinese Academy of Medical Sciences, Beijing, China.

Correspondence: Konglai Zhang, Dept of Epidemiology, Institute of Basic Medical Sciences, Chinese Academy of Medical Sciences, Beijing 100005, China. E-mail: konglai_zhang@163.com

Received: 9 July 2020 | Accepted after revision: 14 July 2020

Author contributions: All authors certify that they have participated sufficiently in this work. Each author certifies that this material has not been submitted to or published in any other publication. All authors approved the final version of the manuscript.

Conflict of interest: H. Chen has nothing to disclose. K. Zhang has nothing to disclose.

\section{Reference}

1 McQuaid CF, McCreesh N, Read JM, et al. The potential impact of COVID-19-related disruption on tuberculosis burden. Eur Respir J 2020; 56: 2001718.

2 National Health Commission. Overview of the epidemic situation of statutory infectious diseases in China in January 2020. www.nhc.gov.cn/jkj/s3578/202002/f1dd61c00acf4e5caf2f755cc48b9063.shtml Date last accessed: May $25,2020$.

3 National Health Commission. Overview of the epidemic situation of statutory infectious diseases in China in Feburary 2020. www.nhc.gov.cn/jkj/s3578/202003/5925e2c60c254d88bc534e7d7b680a19.shtml Date last accessed: May 25, 2020.

4 National Health Commission. Overview of the epidemic situation of statutory infectious diseases in China in March 2020. www.nhc.gov.cn/jkj/s3578/202004/78d3cle01c0644ee978415a13a0e002a.shtml Date last accessed: May 25, 2020.

5 National Health Commission. Overview of the epidemic situation of statutory infectious diseases in China in April 2020. www.nhc.gov.cn/jkj/s5899tg/202006/562eede38f744c10a738ab2b37d806d0.shtml Date last accessed: May 25, 2020.

6 National Health Commission. Overview of the epidemic situation of statutory infectious diseases in China in May 2020. www.nhc.gov.cn/jkj/s5899tg/202006/554a0f964edc46318635eedeca8edd13.shtml Date last accessed: June 30, 2020.

7 Pang Y, Liu Y, Du J, et al. Impact of COVID-19 on tuberculosis control in China. Int J Tuberc Lung Dis 2020; 24: 545-547. 
8 Stochino C, Villa S, Zucchi P, et al. Clinical characteristics of COVID-19 and active tuberculosis co-infection in an Italian reference hospital. Eur Respir J 2020; 56: 2001708.

9 Tadolini M, Codecasa LR, Garcia-Garcia JM, et al. Active tuberculosis, sequelae and COVID-19 co-infection: first cohort of 49 cases. Eur Respir J 2020; 56: 2001398.

10 Motta I, Centis R, D’Ambrosio L, et al. Tuberculosis, COVID-19 and migrants: Preliminary analysis of deaths occurring in 69 patients from two cohorts. Pulmonology 2020; 26: 233-240.

Copyright CERS 2020.

This version is distributed under the terms of the Creative Commons Attribution Non-Commercial Licence 4.0. 